\title{
Plasma metabolomic profiles and immune responses of piglets after weaning and challenge with E. coli
}

\author{
Sugiharto Sugiharto ${ }^{1,2^{*}}$, Mette S Hedemann ${ }^{1}$ and Charlotte Lauridsen ${ }^{1}$
}

\begin{abstract}
Background: The processes of weaning and exposure to pathogenic bacteria induce stress responses, which may alter the metabolism. In this study, we investigated the changes in plasma metabolites and immune responses in piglets in response to the stress induced by weaning and Escherichia coli challenge.

Results: Fecal dry matter decreased $(P=0.003)$ and nearly half (44.4\%) the piglets developed diarrhea on day 2 and 3 postweaning. The concentration of plasma immunoglobulin A was higher $(P<0.001)$ on day 11 postweaning than on day 0 or 4 postweaning. The levels of white blood cells increased continuously $(P<0.001)$ from day 0 to day 11 postweaning. Differences in the percentages of neutrophils $(P=0.029)$ and lymphocytes $(P=0.022)$ were seen, but the neutrophil/lymphocyte ratio did not differ in the period after weaning. A clear separation of the metabolomic profile data for day 0 and day 4 postweaning was observed with a principal components analysis (PCA) scores plot, and the data for day 11 were located between those for day 0 and day 4 postweaning. The plasma levels of proline, taurine, and carnitine were higher, whereas those of betaine, creatine, L-arginine and acetylcarnitine were lower on day 4 postweaning than on day 0 . Levels of lysophosphatidylcholine and phosphatidylcholine were either higher or lower after weaning, depending on the chain lengths or characters of these metabolites.
\end{abstract}

Conclusions: Our results show a clear separation in the plasma metabolomic profiles of piglets that corresponded to the fecal responses to stress on the piglets induced by weaning or exposure to a pathogen (E. coli). These plasma metabolite profiles suggest that the challenges induced proinflammatory responses in the piglets, resulting in postweaning diarrhea, which was associated with higher concentrations of IgA in the plasma.

Keywords: E. coli F18, Immunity, Metabolite, Piglet, Weaning

\section{Introduction}

In modern pig production, weaning is one of the most critical periods during the life of piglets [1] because they are exposed to several stressors. Together with a number of nutritional changes (from sow's milk to solid feed), social changes (mixing with different litters and loss of the sow), and environmental changes (moving from the farrowing unit to the nursery pen), the piglets are exposed to various pathogens in their feed and the environment just as the passive immunity conferred by the antibodies

\footnotetext{
* Correspondence: sugiharto@agrsci.dk

'Department of Animal Science, Faculty of Science and Technology, Aarhus University, AU-Foulum, Tjele 8830, Denmark

${ }^{2}$ Faculty of Animal Science and Agriculture, Diponegoro University, Semarang, Central Java 50275, Indonesia
}

in the sow's milk have diminished [2,3]. For these reasons, weaning has been implicated in the induction of stress responses and an increased susceptibility to infection $[3,4]$.

Changes in the microbial community in the gut may translate to an instability (imbalance) in the gut microbial ecosystem, leading to intestinal disorders $[5,6]$. Beside weaning-related stress, another factor responsible for this unbalanced gut microbiota is the presence of enterotoxigenic Escherichia coli (ETEC) in the guts of piglets [7]. Together with the weaning stress and the change from sow's milk to a cereal-based diet, changes in the microbial composition of the gut during weaning have been suggested to affect the metabolism of piglets [8-10]. Similarly, the regulation of their metabolism 
may be altered when weaned piglets experience intestinal distress [3]. Recently, metabolomic analysis has been introduced as a method to study the metabolism of weaned piglets [9]. With this approach, we studied the metabolomic profiles of postweaning piglet plasma based on liquid chromatography-mass spectrometry (LC-MS) metabolomic data.

The first week after weaning is usually considered the most stressful period for piglets and is associated with intestinal disorders and the development of postweaning diarrhea (PWD) [3,11]. To establish a pig model of weaning-stress-induced intestinal disorder, the piglets in the present study were challenged with $E$. coli F18, a common porcine enteric pathogen, during the first $3 \mathrm{~d}$ after weaning. The purpose of the study was to obtain information on the changes in the plasma metabolites and immune responses of piglets in response to the stress induced by weaning and $E$. coli challenge.

\section{Materials and methods}

\section{Experimental design}

The animal experiment was conducted according to the license obtained from the Danish Animal Experiments Inspectorate, Ministry of Food, Agriculture and Fisheries, Danish Veterinary and Food Administration. The experiment was conducted over an 11-day period after weaning with 18 specific-pathogen-free piglets from three litters. The pigs were weaned at 28-34 d of age (body weight $=9.18 \pm 1.35 \mathrm{~kg}$; mean $\pm \mathrm{SD}$ ) from sows that tested positive for E. coli F18, and were transported from the farrowing unit to the nursery pen. Three pigs of similar weight were housed together in $1.45 \mathrm{~m} \times$ $1.70 \mathrm{~m}$ pens with concrete flooring and sawdust bedding. The weaned piglets had free access to creep feed (without zinc oxide) and fresh water from the time of weaning onward. They were also provided with a milk replacer during the first $4 \mathrm{~d}$ after weaning. The composition and chemical analysis of the creep feed and milk replacer are shown in Table 1. The milk replacer was prepared with an automated wet feeder (Mambo Automix 25, Wit-Mambo Inc., Wommels, Netherlands), in which milk powder was automatically mixed with warm water $\left(45^{\circ} \mathrm{C}\right.$ ) (approx. $150 \mathrm{~g}$ of milk powder in $1 \mathrm{~L}$ of water), and was fed to the piglets on a regular basis.

The bacterial challenge strain (E. coli O138:F18) was administered in the milk replacer, and was provided to the piglets during the first $3 \mathrm{~d}$ after weaning (on day 1 , 2 , and 3 postweaning). Each day, an individual pig was expected to receive $3 \times 10^{8}$ cfu E. coli F18 in $50 \mathrm{~mL}$ of milk replacer. The E. coli F18 inoculum was prepared according to Sugiharto et al. [12]. The challenge strain was isolated at the Danish Veterinary Institute (Frederiksberg, Copenhagen) from the intestinal contents of a pig with PWD. It was found to carry genes for enterotoxins STb, LT,
Table 1 Creep feed and milk replacer compositions

\begin{tabular}{|c|c|c|c|}
\hline \multicolumn{2}{|l|}{ Creep feed $^{\mathrm{a}}$} & \multicolumn{2}{|l|}{ Milk replacer $^{\mathbf{b}}$} \\
\hline Ingredients ${ }^{c}, \%$ & & Ingredients ${ }^{\mathrm{c}}, \%$ & \\
\hline Wheat & 46.80 & Skim milk powder & 50.00 \\
\hline Barley & 25.00 & Whey protein powder & 24.00 \\
\hline Soybean meal & 19.00 & Vegetable oil and fat & 13.00 \\
\hline Protein concentrate & 2.00 & Sugar & 8.00 \\
\hline Palm fat & 1.40 & Wheat flour & 4.00 \\
\hline Other $^{d}$ & 5.80 & & \\
\hline Chemical analysis ${ }^{\mathrm{c}}, \%$ & & Chemical analysis ${ }^{\complement}, \%$ & \\
\hline Crude fat & 3.50 & Crude fat & 14.00 \\
\hline Crude protein & 18.30 & Crude protein & 23.00 \\
\hline Crude ash & 5.30 & Crude ash & 7.00 \\
\hline Sodium & 0.20 & Sodium & 0.47 \\
\hline Calcium & 0.88 & Calcium & 0.75 \\
\hline Phosphorus & 0.54 & Phosphorus & 0.68 \\
\hline Lysine & 1.19 & Lysine & 2.17 \\
\hline Methionine & 0.36 & Methionine and cysteine & 0.92 \\
\hline
\end{tabular}

${ }^{a}$ Creep feed was produced by Dansk Landbrugs Grovvareselskab Amba

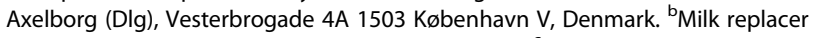
was produced by Vitfoss, 6300 Graasten, Denmark. Information about the ingredients and chemical analysis of the milk replacer and creep feed were provided by the producers. ${ }^{\mathrm{d} H e m o g l o b i n, ~} 1.05 \%$; monocalcium phosphate, $0.90 \%$; calcium carbonate, $0.82 \%$; calcium formate, $0.80 \%$; vitaLys dry, $0.52 \%$; beet molasses, $0.50 \%$; animal feed salt, $0.46 \%$; threonine, $0.11 \%$; DLmethionine, $0.10 \%$; phytase, $0.04 \%$.

EAST1, Shigatoxin 2e, and fimbriae F18. The bacterium was hemolytic when grown on blood agar (Oxoid, Deutschland GmbH, Wesel, Germany) [13].

\section{Sample collection and analysis}

For the complete blood counts and immunoglobulin and metabolomic analyses, blood was collected in EDTAcontaining and heparinized Vacutainers (Vacuette, Greiner Bio-One $\mathrm{GmbH}$, Kremsmünster, Austria) after puncture of the jugular vein on day 0,4 , and 11 postweaning. Fecal samples were collected for bacterial enumeration and dry matter analysis from the rectum of each piglet with rubber gloves (lubricated with glycerin) on day 0, 2, 3, 4, 5, 7, and 11 postweaning. The diarrhea score, based on the consistency of the collected feces $(0=$ normal [hard/ dry and cloddy/firm/soft with shape] or $1=$ diarrhea [soft and liquid/watery and dark/watery and yellow/ foamy and yellow]), was recorded. Throughout the experiment, the health $(0=$ healthy or $1=$ unhealthy $)$ and behavior $(0=$ active or $1=$ listless $)$ of the piglets were also evaluated daily. The samples were collected and observations made on day 0 before the piglets were moved to the nursery pen.

To determine the contents of hemolytic E. coli and total coliform bacteria, approximately $1 \mathrm{~g}$ of feces was suspended in peptone solution $(1: 10, w / v)$ and homogenized with a 
bag mixer (BagMixer100, Interscience, St. Nom, France). Serial 10 -fold dilutions were prepared and $100-\mu \mathrm{L}$ aliquots were plated on blood agar (Oxoid) and McConkey agar (Merck KGaA, Darmstadt, Germany) and incubated aerobically at $37^{\circ} \mathrm{C}$ overnight to count the hemolytic E. coli and total coliform bacteria, respectively. The dry matter content of the feces was determined by freeze-drying the feces samples to a constant weight (in a vacuum at an operating pressure of 0.4 mbar for $48 \mathrm{~h}$ ). Immediately after collection, complete blood counts were performed with a hemocytometer (Cell-Dyne ${ }^{\circledR}$ 3500R, Abbott Diagnostics, Santa Clara, CA, USA). The plasma was obtained after centrifugation of the blood at $2,000 \times g$, and stored at $-20^{\circ} \mathrm{C}$ until the immunoglobulin and metabolomic analyses. The concentrations of immunoglobulin A (IgA) and immunoglobulin G (IgG) in the plasma were measured with commercial kits (Pig Ig ELISA Quantification Kit, Bethyl Laboratories, Montgomery, TX, USA). The samples were tested at dilutions of 1:5,000 and 1:100,000 for plasma IgA and IgG, respectively. The intra-assay coefficients of variation $(\mathrm{CVs})$ for IgA were $1.7 \%-2.4 \%$ and $0.1 \%-4.8 \%$ for the high- and low-titer control samples, respectively, and the interassay CVs were $3.6 \%$ and $4.8 \%$, respectively. For IgG, the intra-assay CVs were $2.6 \%-3.1 \%$ and $1.9 \%-2.6 \%$ for the high- and low-titer control samples, respectively, and the interassay CVs were $2.5 \%$ and $2.4 \%$, respectively. The assays were performed in duplicate and according to the manufacturer's instructions.

The plasma samples were prepared for LC-MS analysis by mixing the plasma $(100 \mu \mathrm{L})$ with $200 \mu \mathrm{L}$ of acetonitrile/ formic acid $(99: 1, \mathrm{v} / \mathrm{v})$ containing a $10-\mu \mathrm{mol} / \mathrm{L}$ internal standard mix of glycocholic acid (glycine- $1{ }^{13} \mathrm{C}$ ), betainetrimethyl-d9 hydrochloride, and choline chloride-trimethyld9 (Sigma-Aldrich, St. Louis, MO, USA). The samples were shaken and incubated at $4^{\circ} \mathrm{C}$ for $20 \mathrm{~min}$ for deproteinization. The supernatants were collected after centrifugation at 13,200 $\times g$ for $10 \mathrm{~min}$ and injected into the LC-MS apparatus. For the LC-MS analysis, an Ultimate 3000 (Dionex, Sunnyvale, CA, USA) high-performance liquid chromatography (HPLC) system was coupled to a MicrOTOF-Q II mass spectrometer (Bruker Daltonik $\mathrm{GmbH}$, Bremen, Germany) operating in $\mathrm{ESI}^{+}$mode. The scan range was $50-1,000 \mathrm{~m} / z$; the capillary voltage was 4,500 V; the nebulizing gas pressure was $1.8 \mathrm{bar}$; and the drying gas flow and temperature were $8.0 \mathrm{~L} / \mathrm{min}$ and $200^{\circ} \mathrm{C}$, respectively. Lithium formate at a concentration of $5 \mathrm{mmol} / \mathrm{L}$ in water/isopropanol/formic acid (50:50:0.2, $\mathrm{v} / \mathrm{v} / \mathrm{v})$ was used as the external calibrant and was injected at the beginning of each chromatographic run. For subsequent metabolite identification, an MS/MS analysis was performed using argon as the collision gas, with collisions at energies from 6 to $60 \mathrm{eV}$. Chromatographic separation was performed on an Ascentis ${ }^{\circledR}$ Express HILIC HPLC column $(2.7 \mu \mathrm{m}, 2.1 \mathrm{~mm} \times 100 \mathrm{~mm})$ used with a precolumn
$(2.7 \mu \mathrm{m}, 2.1 \mathrm{~mm} \times 50 \mathrm{~mm})$. The column was held at $30^{\circ} \mathrm{C}$ and the injection volume was $5 \mu \mathrm{L}$. Mobile phase A consisted of ammonium acetate buffer $(5 \mathrm{mmol} / \mathrm{L}$ at $\mathrm{pH} 4$, adjusted with formic acid) and mobile phase B consisted of acetonitrile/formic acid (100:0.025, v/v). The column was equilibrated for 5 min before the gradient commenced at $90 \% \mathrm{~B}$ for $1 \mathrm{~min}$ and then decreased linearly to $10 \% \mathrm{~B}$ within $15 \mathrm{~min}$. The mobile phase was maintained under isocratic conditions $(10 \% \mathrm{~B})$ for $5 \mathrm{~min}$ and then returned to $90 \% \mathrm{~B}$. The total analysis time was $21 \mathrm{~min}$ and the flow rate was $100 \mu \mathrm{L} / \mathrm{min}$. A sample of pooled plasma from the piglets was reinjected after each six samples for quality control of the LC-MS run. The acquired mass spectra were calibrated and converted into mzXML file format using CompassXport (Bruker Daltonik GmbH), before the data were analyzed with XCMS Online, which is freely available at http://xcmsonline.scripps.edu/ [14]. The metabolites were identified based on accurate mass and mass spectrometric fragmentation patterns by searching the METLIN databases (http://metlin.scripps.edu/index.php). Standards were used to confirm the identities of the compounds when available.

\section{Statistical analysis}

The effects of the sampling day on the incidence of PWD, health, and behavior of the piglets were analyzed using the GLIMMIX procedure of SAS (SAS Inst. Inc., Cary, NC, USA). The MIXED procedure was used to analyze the effects of the sampling day on the fecal dry matter, bacterial population counts in the feces, concentrations of IgG and IgA in the plasma, and the hematological parameters. A Spearman correlation analysis was used to investigate the relationship between the incidence of PWD, health, and behavior. The individual piglet was considered to be the experimental unit for the statistical evaluations. Litter was included in the model as a random effect. The counts of bacteria (cfu), white blood cells (WBC), and red blood cells (RBC) were log-transformed before the analysis. The data are presented as least-squares means and standard errors of the means (SE). The differences were considered significant when $P<0.05$.

For the metabolomic data, a principal components analysis and the $P$ values for the differences in the intensities of metabolite ions between day 0 and day 4 postweaning were calculated automatically by the XCMS Online system. The false discovery rate (FDR) $q$ values, to correct for multiple comparisons, were also calculated automatically by the system, with the significance threshold set at $q<0.25$ [15].

\section{Results}

\section{General health of the piglets}

One of 18 piglets showed signs of diarrhea just before it was moved to the nursery pen, and nearly half (44.4\%) the piglets developed diarrhea on day 2 or day 3 postweaning 
(Figure 1). The dry matter in the feces decreased $(P=0.003)$ after weaning and challenge with $E$. coli (Figure 1). In general, the piglets were healthy and active for the entire experimental period (data not shown). The health of the piglets correlated with their behavior $(r=0.933, P<0.001)$. The occurrence of diarrhea did not correlate with the health or behavior of the piglets $(P>0.05$; data not shown).

\section{Bacterial counts}

The counts of hemolytic E. coli and total coliform bacteria in the fecal samples increased $(P<0.001)$ following weaning and challenge with $E$. coli, plateaued, and then declined by the end of the experiment (Figure 2).

\section{Immune responses and hematological parameters}

The concentration of IgA in the plasma was higher on day 11 postweaning than on day 0 or day 4 postweaning $(P<$ 0.001 ; Figure 3$)$. The concentration of plasma IgG did not change during the postweaning period $(P=0.158)$.

The hematological parameters of the piglets are presented in Table 2. The total number of WBC increased continuously from day 0 to day 11 postweaning $(P<$ $0.001)$. The percentage of eosinophils was increased on day 4 postweaning (compared with that on day 0 ), and then remained unchanged until day 11 postweaning. The percentage of neutrophils and the concentration of hemoglobin did not change from day 0 to day 4 postweaning, but had increased by day 11 postweaning $(P<$ $0.05)$. The percentage of lymphocytes and the hematocrit did not change between day 0 and day 4 postweaning, but had decreased by day 11 postweaning $(P<0.05)$.

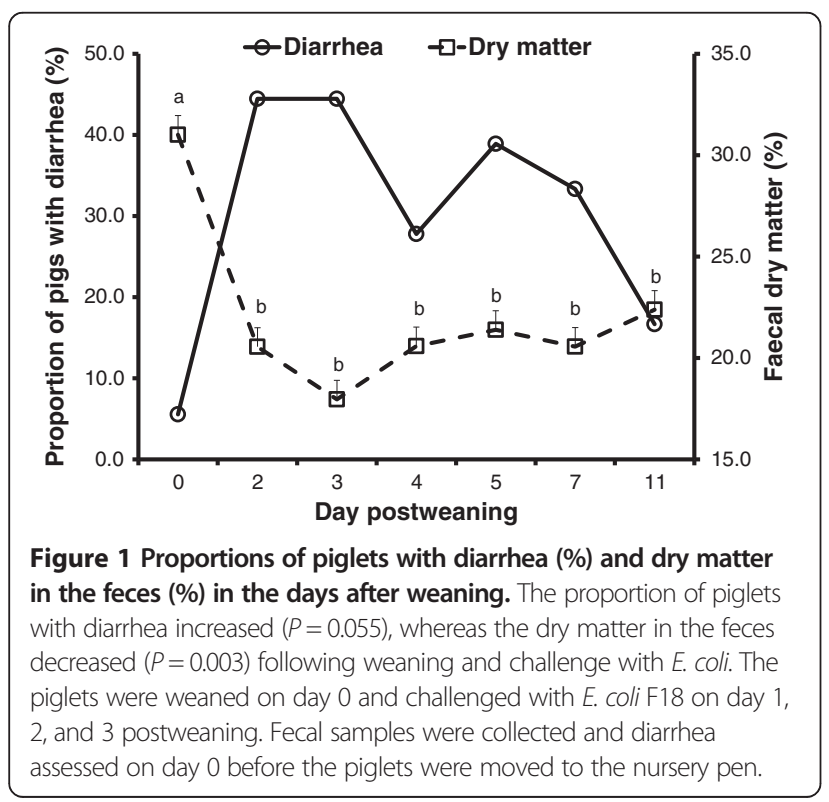

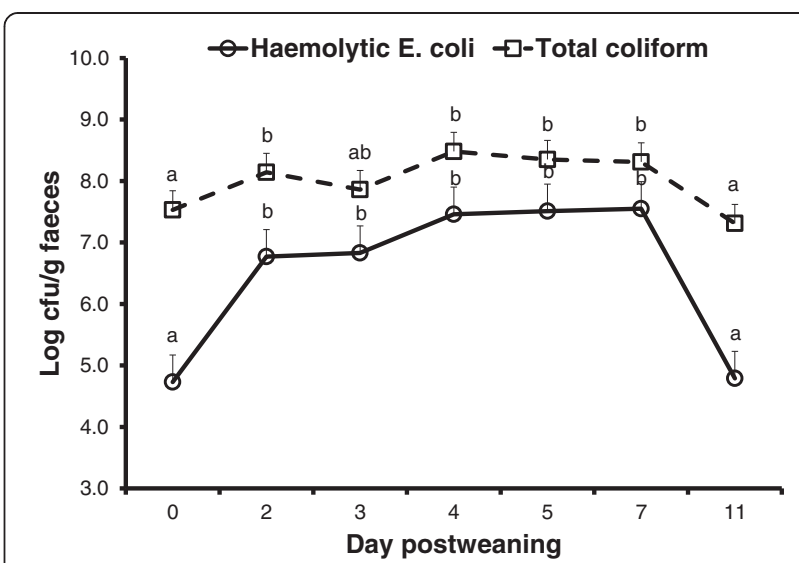

Figure 2 Fecal shedding of hemolytic $E$. coli and total coliform bacteria (log cfu/g feces) in the postweaning period. The counts of hemolytic $E$. coli and total coliform bacteria increased $(P<0.001)$ following weaning and challenge with E. coli, plateaued, and then declined at the end of experimental period. The piglets were weaned on day 0 and challenged with E. coli F18 on day 1, 2, and 3 postweaning.

\section{Metabolomic profile}

A total of 54 plasma samples collected on day 0,4 , and 11 postweaning were included in the metabolomic analysis. The PCA model showed a clear separation of the metabolomic data according to days postweaning. Along the horizontal axis of the PCA (PC1), samples from day 11 postweaning were located between those from day 0 and those from day 4 postweaning (Figure 4).

The metabolite ions with the greatest influence on the differences observed between day 0 and day 4 postweaning were located and identified (Table 3). L-Proline/D-proline, taurine, creatine, carnitine, and L-arginine were identified based on their characteristic fragmentation patterns and retention times. Acetylcarnitine was identified based on its

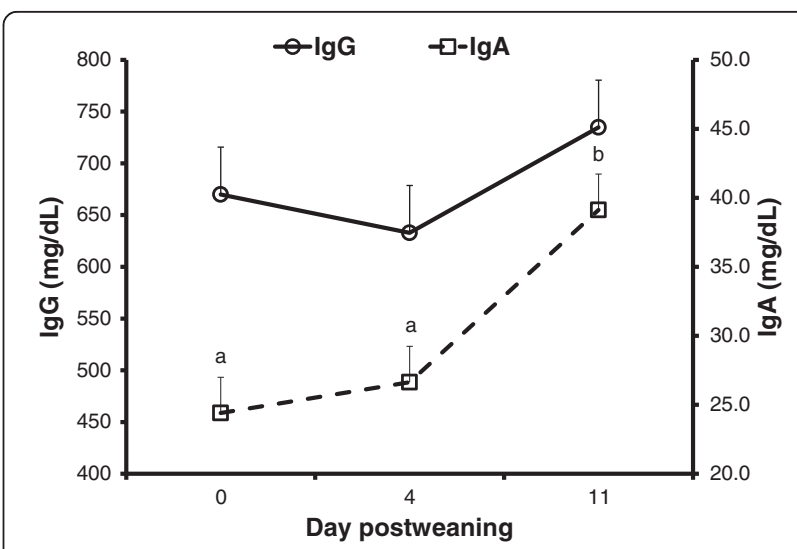

Figure 3 Concentrations of plasma $\lg G$ and $\lg A(\mathrm{mg} / \mathrm{dL})$ on day 0,4 , and 11 postweaning. The concentration of IgA was higher $(P<0.001)$ on day 11 postweaning than on day 0 or 4 postweaning. The piglets were weaned on day 0 and challenged with $E$. coli F18 on day 1, 2, and 3 postweaning. Plasma was collected on day 0 before the piglets were moved to the nursery pen. 
Table 2 Hematological parameters of piglets on day 0, 4 and 11 postweaning

\begin{tabular}{|c|c|c|c|c|c|}
\hline \multirow[t]{2}{*}{ Items } & \multicolumn{3}{|c|}{ Day postweaning $^{a}$} & \multirow[t]{2}{*}{ SE } & \multirow{2}{*}{$\begin{array}{c}P \\
\text { value }\end{array}$} \\
\hline & $0^{b}$ & 4 & 11 & & \\
\hline$\overline{\mathrm{WBC}^{\mathrm{C}}, \times 10^{9} / \mathrm{L}}$ & $10.47^{\mathrm{a}}$ & $13.80^{b}$ & $17.38^{c}$ & $<0.01$ & $<0.001$ \\
\hline Neutrophils ${ }^{\mathrm{d}}, \%$ & $32.49^{a}$ & $29.50^{\mathrm{a}}$ & $39.93^{b}$ & 5.42 & 0.029 \\
\hline Lymphocytes ${ }^{\mathrm{d}}, \%$ & $61.00^{\mathrm{a}}$ & $62.78^{\mathrm{a}}$ & $52.85^{\mathrm{b}}$ & 5.23 & 0.022 \\
\hline$N L R^{e}$ & 0.62 & 0.56 & 0.79 & 0.14 & 0.093 \\
\hline Monocytes $^{d}, \%$ & 5.90 & 6.59 & 6.12 & 1.28 & 0.928 \\
\hline Eosinophils ${ }^{\mathrm{d}}, \%$ & $0.35^{\mathrm{a}}$ & $0.95^{b}$ & $0.92^{\mathrm{b}}$ & 0.19 & 0.001 \\
\hline Basophils $^{\mathrm{d}}, \%$ & 0.11 & 0.04 & 0.03 & 0.04 & 0.190 \\
\hline $\mathrm{RBC}^{\mathrm{f}}, \times 10^{12} / \mathrm{L}$ & 6.61 & 6.46 & 6.46 & 0.00 & 0.497 \\
\hline $\mathrm{Hb}^{\mathrm{g}}, \mathrm{mmol} / \mathrm{L}$ & $7.27^{\mathrm{a}}$ & $6.93^{\mathrm{a}}$ & $11.44^{\mathrm{b}}$ & 0.37 & $<0.001$ \\
\hline Hematocrit, $\%$ & $36.50^{\mathrm{a}}$ & $35.08^{\mathrm{ab}}$ & $33.75^{b}$ & 1.47 & 0.021 \\
\hline
\end{tabular}

${ }^{\mathrm{a}}$ The piglets were weaned on day 0 and challenged with E. coli F18 on day 1, 2 , and 3 postweaning. ${ }^{b}$ Blood was collected on day 0 before the piglets were moved to the nursery pen. ${ }^{\mathrm{C}} \mathrm{WBC}$, total white blood cells. ${ }^{\mathrm{d}}$ The values are presented as percentages of the total WBC. ${ }^{e} \mathrm{NLR}$, neutrophil/lymphocyte ratio; ${ }^{\mathrm{f}} \mathrm{RBC}$, red blood cells; ${ }^{9} \mathrm{Hb}$, hemoglobin.

fragmentation pattern, whereas betaine was identified by comparison with a betaine standard. The levels of proline, taurine, and carnitine in the plasma were increased, whereas those of betaine, creatine, L-arginine, and acetylcarnitine were reduced on day 4 postweaning compared with the levels on day 0 . Several species of lysophosphatidylcholine (lysoPC) were identified in the plasma and the levels of these metabolites either increased or decreased after weaning, depending on their chain lengths and saturation. The different species of phosphatidylcholine (PC) could not be distinguished in the analysis because their fragmentation patterns were identical. The levels of these compounds were increased or reduced after weaning and challenge with $E$. coli. Of all the metabolites identified in

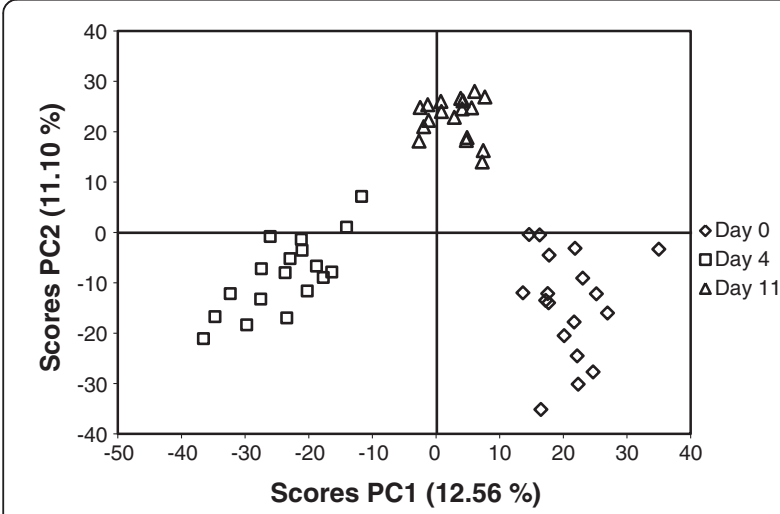

Figure 4 PCA scores plots of pig plasma collected on day 0,4 , and 11 postweaning. The PCA model shows a clear separation of the data according to the days postweaning. The piglets were weaned on day 0 and challenged with E. coli F18 on day 1, 2, and 3 postweaning. Plasma was collected on day 0 before the piglets were moved to the nursery pen. the plasma, an unidentified PC with a mass-to-charge ratio of 678.5 seemed to be the compound most strongly elevated in response to weaning and challenge with E. coli.

\section{Discussion}

Weaning is a stressful event and is associated with intestinal distress and increased exposure to enteric pathogens from feed and the environment [1,4]. To model such stressful conditions, the piglets in this study, which were genetically susceptible to $E$. coli $\mathrm{F} 18$, were weaned and challenged with E. coli F18. Weaning has been associated with changes of the metabolism of piglets $[3,9]$. To study the metabolic changes in piglets during the period after weaning, we conducted an LC-MS-based metabolomic analysis of the plasma from piglets, collected at different time points after weaning. As shown in the PCA scores plot, there was a separation between the metabolic profiles according to the days after weaning, indicating changes in the metabolic patterns of the piglets during the postweaning period. The first week (5-7 d) after weaning is considered the most stressful period for piglets, when intestinal dysfunction and changes in the metabolism can occur $[3,11]$. Consistent with this assumption, a clear separation was observed in the serum metabolites between day 0 and day 4 postweaning in the PCA model. Interestingly, the samples from day 11 postweaning were located between those from day 0 and day 4 postweaning along the horizontal axis of the PCA (PC1). This observation suggests that the piglets on day 11 postweaning tended to resume a metabolic state similar to that observed on day 0 . In this study, we noticed an increase in the incidence of PWD and fecal shedding of hemolytic E. coli during the first week postweaning, but these parameters had decreased on day 11 postweaning. Based on the pattern of metabolic changes indicated by the PCA model and the development of PWD and fecal shedding of hemolytic $E$. coli, we inferred a potential relationship between the metabolomic profiles of piglets and weaning- and E. coli-induced PWD during the early postweaning period.

In this study, we noted that the responses of some blood immune parameters to weaning and E. coli challenge were variable and dynamic. Whereas no difference was observed in plasma IgG in the days after weaning, the plasma IgA concentrations increased with weaning and E. coli F18 challenge. It has been reported that physiological and immunological changes occur with age and weaning $[2,16]$. In this context, we realize that our failure to include a control group (piglets not challenged with $E$. coli F18) in the present study limits our interpretation of the results, and that developmental changes may have contributed to some of the changes observed. Previous studies have shown that E. coli F18 infection enhances IgA levels in the sera and intestinal washes of postweaning piglets [17], and that once IgA has been 
Table 3 List of metabolites identified in the metabolomic analysis ${ }^{a}$

\begin{tabular}{|c|c|c|c|c|c|c|c|}
\hline Metabolites & Retention time, min & $\mathrm{m} / \mathrm{z}$ & Mass accuracy, ppm & Fold change $^{b}$ & Up/down & $P$ value ${ }^{c}$ & FDR q value $^{c}$ \\
\hline L-Proline/D-Proline & 9.81 & 116.0702 & 3.45 & 1.35 & $\uparrow$ & 0.0035 & 0.0046 \\
\hline Betaine & 10.93 & 118.0857 & 5.08 & 1.60 & $\downarrow$ & $<0.0001$ & $<0.0001$ \\
\hline Taurine & 7.15 & 126.0225 & 4.76 & 1.49 & $\uparrow$ & 0.0003 & 0.0005 \\
\hline Creatine & 9.99 & 132.0760 & 6.06 & 3.35 & $\downarrow$ & 0.0002 & 0.0003 \\
\hline Carnitine & 10.78 & 162.1116 & 5.55 & 1.45 & $\uparrow$ & $<0.0001$ & $<0.0001$ \\
\hline L-Arginine & 11.02 & 175.1177 & 7.42 & 1.82 & $\downarrow$ & $<0.0001$ & $<0.0001$ \\
\hline Acetylcarnitine & 10.71 & 204.1218 & 5.88 & 1.24 & $\downarrow$ & 0.0003 & 0.0005 \\
\hline LysoPC 14:0 & 9.49 & 468.3054 & 6.62 & 3.04 & $\uparrow$ & $<0.0001$ & $<0.0001$ \\
\hline LysoPC 16:1 & 9.39 & 494.3207 & 6.88 & 1.95 & $\downarrow$ & $<0.0001$ & $<0.0001$ \\
\hline LysoPC 16:0 & 9.31 & 496.3357 & 8.26 & 1.20 & $\downarrow$ & $<0.0001$ & $<0.0001$ \\
\hline LysoPC 16:0 [M + Na] & 9.32 & 518.3171 & 8.87 & 1.19 & $\downarrow$ & 0.0015 & 0.0021 \\
\hline LysoPC 18:2 & 9.31 & 520.3351 & 9.03 & 1.90 & $\downarrow$ & $<0.0001$ & $<0.0001$ \\
\hline LysoPC 18:0 & 9.07 & 524.3667 & 8.39 & 1.10 & $\downarrow$ & 0.0428 & 0.0397 \\
\hline LysoPC 17:0 $[\mathrm{K}+\mathrm{Na}]^{+}$ & 9.17 & 548.3095 & 3.28 & 1.40 & $\uparrow$ & $<0.0001$ & $<0.0001$ \\
\hline UI PC & 8.20 & 678.5028 & 5.90 & 19.75 & $\uparrow$ & $<0.0001$ & $<0.0001$ \\
\hline UI PC & 8.05 & 758.5608 & 11.34 & 1.43 & $\downarrow$ & $<0.0001$ & $<0.0001$ \\
\hline UI PC & 7.78 & 810.5916 & 11.23 & 1.31 & $\downarrow$ & $<0.0001$ & $<0.0001$ \\
\hline $\mathrm{UI} P C[\mathrm{M}+\mathrm{Na}]^{+}$ & 7.75 & 834.5922 & 7.31 & 1.26 & $\uparrow$ & 0.0001 & 0.0003 \\
\hline
\end{tabular}

stimulated (by pathogens), it may persist for a long period (the half-life of IgA is $6 \mathrm{~d}$ [18]). Therefore, we inferred that the enhanced IgA concentration was primarily attributable to the $E$. coli F18 challenge, because weaning is normally associated with a reduced concentration of IgA (with the removal of the IgA derived from the sow's milk) [4]. The fact that we weaned the piglets at 28-34 d of age may also support our inference, because it is assumed that pigs are physiologically and immunologically competent by $35 \mathrm{~d}$ of age [16].

Our results show that the number of total WBC continued to increase from day 0 to day 4 and 11 postweaning. This is consistent with a study of unchallenged postweaning piglets (weaned at $21 \mathrm{~d}$ of age) by Davis et al. [19], which showed increased total WBC following weaning (and age), i.e., 3.51, 3.92, 6.53, and $8.82 \times 10^{3} / \mathrm{mL}$ on day $0,2,10$, and 27 postweaning, respectively. Therefore, it seems difficult to attribute the increased total WBC in our piglets to the effects of the stress induced by weaning and challenge with $E$. coli. Moreover, although differences in the percentages of neutrophils and lymphocytes were seen in the postweaning period, the ratio of neutrophils to lymphocytes (an indicator of the pig's response to stress) did not change during this period, suggesting that the observed differences in the percentages of neutrophils and lymphocytes were probably age-related and were not due to weaning and challenge with E. coli [19].
In the metabolomic analysis, seven lysoPC species were identified in the plasma of pigs and their levels changed during the experiment, with two species increasing and five species decreasing when the piglets were weaned and challenged with E. coli. LysoPC is a bioactive phospholipid involved in inflammatory processes [20]. Therefore, the elevated levels of the two lysoPC species in the plasma of postweaning pigs were probably related to weaning- and E. coli-induced inflammation and the development of PWD [2,4], which were apparent as increased fecal shedding of hemolytic E. coli and the occurrence of PWD during the first week after weaning in this study. LysoPC is also known as an important intermediate in the degradation and biosynthesis of PC [21]. In this study, we observed a substantial increase in the levels of a PC with a mass-to-charge ratio of 678.5 in the plasma (an indicator of increased PC formation) in the postweaning pigs. This increase in PC biosynthesis might consequently reduce the availability of some particular lysoPC species in the circulatory system, and may partly explain the reductions in five lysoPC species in the plasma of postweaning pigs in the present study. Increased gut colonization by ETEC is commonly seen in postweaning pigs [4], and accordingly, increased fecal shedding of hemolytic E. coli was observed in our pigs after weaning. ETEC colonization may increase the production and/or expression of 
proinflammatory molecules in the pig gut $[2,4]$, and these molecules can react with free radicals, leading to cell membrane damage [22]. Because PC is the major phospholipid component of mammalian cell membranes [23], the increased formation of the two particular PCs observed in this study is most reasonably ascribed to an increased need in these PCs for membrane biogenesis during the early postweaning period. We also observed two unidentified species of PC in the plasma, the levels of which decreased. The reduction in these plasma PCs was probably associated with the enhanced degradation of some specific type of PC during the inflammation-related processes around weaning $[24,25]$, resulting in the increased levels of particular lysoPC species (as described above). Taken together, these data suggest that PC and lysoPC respond differently to weaning and exposure to pathogens, depending on their chain lengths or the molecular characteristics of these metabolites.

Betaine, creatine, and L-arginine have been reported to confer protective effects against oxidative stress [26-28]. In our study, the plasma levels of these compounds decreased upon weaning and exposure to $E$. coli. The inhibition of the antioxidant system, leading to an inflammatory state and the development of PWD in pigs after weaning [29], might partly explain this circumstance. In this study, the increase in carnitine was observed in the plasma of pigs after weaning. Carnitine is an important compound with roles in the intermediary metabolism. Thus, generating adequate levels of carnitine could be one attempt by the piglets to prevent metabolic disturbance and maintain normal metabolic functions during the period after weaning [30]. In contrast to carnitine, the level of acetylcarnitine, an acetyl derivative of carnitine and a byproduct of mitochondrial $\beta$-oxidation, decreased after weaning. Zhao et al. [31] reported that the levels of plasma acylcarnitine may indicate the extent of fatty acid $\beta$-oxidation and the energy status of animals. However, the reduction in plasma acylcarnitine remains unexplained in this study because we did not measure the feed intake of the piglets throughout the experiment. The plasma levels of proline increased noticeably in the piglets after weaning. The upregulation of proline biosynthesis seems to be a response mechanism of piglets to the stress and/or oxidative stress induced by weaning and exposure to $E$. coli [32], apparent as an increased fecal content of hemolytic E. coli and an increased incidence of PWD. Taurine is one of the most abundant free amino acids in animals and is present at high concentrations in WBC [33]. In this study, the increased plasma levels of taurine paralleled the increases in the total WBC concentration. Hence, the observed increased production of taurine in the piglets after weaning does not seem to be associated with weaning stress, but instead supported the development of the pig immune system as the pigs grew older.

\section{Conclusions}

Our results showed a clear separation in the plasma metabolomic profiles of pigs in the days after weaning that corresponded to the fecal response to stresses on the piglets, i.e., weaning and exposure to pathogens (E. coli). Based on the plasma metabolite profiles, these challenges might induce proinflammatory responses in piglets. The challenges also induced PWD and increased the concentration of IgA in the plasma of piglets.

\section{Competing interests}

The study was partly funded by Arla Foods Amba, Denmark, and partly by a $\mathrm{PhD}$ scholarship received from the Directorate General of Higher Education, Ministry of Education and Culture, Republic of Indonesia. The authors declare that they have no conflicts of interest.

\section{Authors' contributions}

SS performed the animal study and drafted the overall manuscript; MSH performed the metabolomic analysis and revised the drafted manuscript; and $\mathrm{CL}$ was the project coordinator, designed the experiment, and revised the drafted manuscript. All authors read and approved the final manuscript.

\section{Acknowledgments}

The authors would like to thank Malene Cilieborg, KU-Life (Copenhagen University), Denmark, who kindly provided E. coli strain O138:F18. We thank Mette Lykkegaard Jørgensen and Inger Marie Jepsen for their technical assistance during the experiment.

Received: 11 October 2013 Accepted: 7 March 2014

Published: 14 March 2014

\section{References}

1. Boudry C, Dehoux J-P, Portetelle D, Buldgen A: Bovine colostrum as a natural growth promoter for newly weaned piglets: a review. Biotechnol Agron Soc Environ 2008, 12:157-170.

2. Pié S, Lallès JP, Blazy F, Laffitte J, Sève B, Oswald IP: Weaning is associated with an upregulation of expression of inflammatory cytokines in the intestine of piglets. J Nutr 2004, 134:641-647.

3. Campbell JM, Crenshaw JD, Polo J: The biological stress of early weaned piglets. J Anim Sci Biotechnol 2013, 4:19.

4. Heo JM, Opapeju FO, Pluske JR, Kim JK, Hampson DJ, Nyachoti CM: Gastrointestinal health and function in weaned pigs: a review of feeding strategies to control post-weaning diarrhoea without using in-feed antimicrobial compounds. J Anim Physiol Anim Nutr 2013, 97:207-237.

5. Sekirov I, Finlay BB: The role of the intestinal microbiota in enteric infection. J Physiol 2009, 587:4159-4167.

6. Cheng J, Palva AM, de Vos WM, Satokari R: Contribution of the intestinal microbiota to human health: from birth to 100 years of age. Curr Top Microbiol Immunol 2013, 358:323-346.

7. Hinton M, Hampson DJ, Hampson E, Linton AH: A comparison of the ecology of Escherichia coli in the intestine of healthy unweaned pigs and pigs after weaning. J Appl Bacteriol 1985, 58:471-477.

8. Dividich $J$, Sève $B$ : Effects of underfeeding during the weaning period on growth, metabolism, and hormonal adjustments in the piglet. Domest Anim Endocrinol 2000, 19:63-74.

9. He Q, Tang H, Ren P, Kong X, Wu G, Yin Y, Wang Y: Dietary supplementation with L-arginine partially counteracts serum metabonome induced by weaning stress in piglets. J Proteome Res 2011, 10:5214-5221.

10. Frick JS, Autenrieth IB: The gut microflora and its variety of roles in health and disease. Curr Top Microbiol Immunol 2013, 358:273-289.

11. Pluske JR: Feed- and feed additives-related aspects of gut health and development in weanling pigs. J Anim Sci Biotechnol 2013, 4:1.

12. Sugiharto, Jensen BB, Lauridsen C: Development an ex vivo model for investigating the bacterial association to the gut epithelium of pigs. J Anim Sci 2012, 90(suppl 4):397-399.

13. Frydendahl K, Jensen TK, Andersen JS, Fredholm M, Evans G: Association between the porcine F18 receptor genotype and phenotype and susceptibility to colonisation and postweaning diarrhoea caused by 0138:F18. Vet Microbiol 2003, 93:39-51. 
14. Tautenhahn R, Patti GJ, Rinehart D, Siuzdak G: XCMS online: a web-based platform to process untargeted metabolomic data. Anal Chem 2012, 84:5035-5039

15. Storey JD, Tibshirani R: Statistical significance for genomewide studies. Proc Natl Acad Sci 2003, 100:9440-9445.

16. Kick AR, Tompkins MB, Flowers WL, Whisnant CS, Almond GW: Effect of stress associated with weaning on the adaptive immune system in pigs. J Anim Sci 2012, 90:649-656.

17. Sarrazin E, Bertschinger HU: Role of fimbriae F18 for actively acquired immunity against porcine enterotoxigenic Escherichia coli. Vet Microbiol 1997, 54:133-144

18. Ogra PL, Lamm ME, McGhee JR, Mestecky J, Strober W, Bienenstock J: Handbook of Mucosal Immunology. San Diego, California: Academic Press, Inc:; 1994

19. Davis ME, Sears SC, Apple JK, Maxwell CV, Johnson ZB: Effect of weaning age and commingling after the nursery phase of pigs in a wean-to-finish facility on growth, and humoral and behavioral indicators of well-being. J Anim Sci 2006, 84:743-756.

20. Gómez-Muñoz A, O'Brien L, Hundal R, Steinbrecher UP: Lysophosphatidylcholine stimulates phospholipase $\mathrm{D}$ activity in mouse peritoneal macrophages. $J$ Lipid Res 1999, 40:988-993.

21. Jantscheff P, Schlesinger M, Fritzsche J, Taylor LA, Graeser R, Kirfel G, Fürst DO, Massing U, Bendas G: Lysophosphatidylcholine pretreatment reduces VLA-4 and P-Selectin-mediated B16.F10 melanoma cell adhesion in vitro and inhibits metastasis-like lung invasion in vivo. Mol Cancer Ther 2011, 10:186-197.

22. Khansari N, Shakiba Y, Mahmoudi M: Chronic inflammation and oxidative stress as a major cause of age-related diseases and cancer. Recent Pat Inflamm Allergy Drug Discov 2009, 3:73-80.

23. Nohturfft A, Zhang SC: Coordination of lipid metabolism in membrane biogenesis. Annu Rev Cell Dev Biol 2009, 25:539-566

24. Lindahl M, Bruhn R, Tagesson C: Lysophosphatidylcholine and the inflammatory action of neutrophils. Scand J Clin Lab Invest 1988, 48:303-311.

25. Wu Y, Lau B, Smith S, Troyan K, Barnett-Foster DE: Enteropathogenic Escherichic coli infection triggers host phospholipid metabolism perturbations. Infect Immun 2004, 72:6764-6772.

26. Ganesan B, Anandan R, Lakshmanan PT: Studies on the protective effects of betaine against oxidative damage during experimentally induced restraint stress in Wistar albino rats. Cell Stress Chaperones 2011, 16:641-665.

27. Sestili P, Martinelli C, Colombo E, Barbieri E, Potenza L, Sartini S, Fimognari C: Creatine as an antioxidant. Amino Acids 2011, 40:1385-1396.

28. Lin WT, Yang SC, Chen KT, Huang CC, Lee NY: Protective effects of $L$-arginine on pulmonary oxidative stress and antioxidant defenses during exhaustive exercise in rats. Acta Pharmacol Sin 2005, 2:992-999.

29. Zhu LH, Zhao KL, Chen XL, Xu JX: Impact of weaning and an antioxidant blend on intestinal barrier function and antioxidant status in pigs. J Anim Sci 2012, 90:2581-2589.

30. Kouttab NM, Gallo LL, Ford D, Galanos C, Chirigos M: Carnitine and derivatives in experimental infections. In Carnitine Today. Edited by Simone CD, Famularo G. US: Landes Bioscience, Springer-Verlag; 1997:171-185.

31. Zhao X, Peter A, Fritsche J, Elcnerova M, Fritsche A, Häring HU, Schleicher $E D, X u G$, Lehmann R: Changes of the plasma metabolome during an oral glucose tolerance test: is there more than glucose to look at? Am J Physiol Endocrinol Metab 2009, 296:E384-E393.

32. Krishnan N, Dickman MB, Becker DF: Proline modulates the intracellular redox environment and protects mammalian cells against oxidative stress. Free Radic Biol Med 2008, 44:671-681.

33. Marcinkiewicz J, Kontny E: Taurine and inflammatory diseases. Amino Acids 2012, doi:10.1007/s00726-012-1361-4.

doi:10.1186/2049-1891-5-17

Cite this article as: Sugiharto et al.: Plasma metabolomic profiles and immune responses of piglets after weaning and challenge with $E$. coli. Journal of Animal Science and Biotechnology 2014 5:17.

\section{Submit your next manuscript to BioMed Central and take full advantage of:}

- Convenient online submission

- Thorough peer review

- No space constraints or color figure charges

- Immediate publication on acceptance

- Inclusion in PubMed, CAS, Scopus and Google Scholar

- Research which is freely available for redistribution 